Is There Ingroup Favoritism in the NBA?

by

Andreas J. Apostolatos

Paul M. Sommers

September, 2006

MIDDLEBURY COLLEGE ECONOMICS DISCUSSION PAPER NO. 06-13

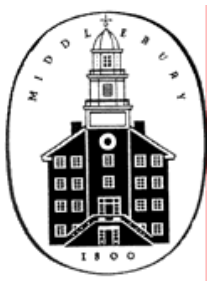

Department of Economics

Middlebury College

Middlebury, Vermont 05753

psommers@middlebury.edu

JEL \#: J710, L830 


\section{Ingroup Favoritism in the NBA?}

Gramm and Schnell [“Difficult Choices: Crossing the Picket Line During the 1987 National Football League Strike,” Journal of Labor Economics, v. 12, no. 1 (January 1994), pp. 41-71] found that NFL strikers in 1987 were more likely to cross the picket line when their union representative belonged to a different race. This finding, in turn, raises the question of whether in a sports league dominated by black athletes, such as the National Basketball Association (NBA), a team with relatively more black players wins more games if their head coach is also black.

To determine whether there is any effect of the interaction between the racial composition of a sports team and the race of the team's coach on team performance, we examined the performance of all twenty-nine teams in the NBA in the 2005-06 season. We regressed the team's winning percentage against the opponents' field-goal percentage and the team's own fieldgoal percentage; the percentage of black players on the team's roster who competed in ten or more games; a binary variable for the coach's race; and an interaction term between the percentage of black players on the roster and the race of the team's coach. (All data as well as pictures of players and coaches are from www.nba.com and www.basketball-reference.com .) As expected, the effects of opponents' field-goal percentage and the team’s own field-goal percentage were negative $(p=.021)$ and positive $(p=.022)$, respectively. The percentage of black players on the team roster was not significant $(p=.407)$. Black coaches led typically weaker teams $(p=.049)$. Surprisingly, however, the estimated coefficient on the interaction term between black roster composition and the race of the team's head coach was positive and marginally significant $(p=.056)$. That is, an increasingly black team played better for a black coach. Moreover, the positive coefficient on the interaction term more than offset the negative coefficient on the black coach binary variable. 
The results presented here for the 2005-06 NBA season suggest that employees, in general, might perform better when they can identify closer (by race) to their workplace authority figure. But, does this manifestation of ingroup favoritism carry over to other professional team sports with a diversity of racial/ethnic groups? Or, is the utility derived from winning in other sports much greater than the disutility of playing for a coach or manager who belongs to a different race? 